\title{
ENKELE PERSPEKTIEWE OP MOTIVERING *
}

\author{
A.J. VAN WYK \\ DEPARTEMENT BEDRYFSIELKUNDE \\ UNIVERSITEIT VAN STELLENBOSCH
}

\begin{abstract}
Different motivational theories in the literature seem to claim unique explanations of motivational behaviour. When these theories are evaluated against basic concepts and the process of motivation, it becomes clear that theory building in motivational terms really focuses on the same basic phenomenon. The implications and practical applications of the more job related contemporary theories of motivation are discussed.
\end{abstract}

Daar bestaan geen twyfel dat die motivering van werknemers as een van die belangrikste bepalende faktore van organisatoriese sukses beskou kan word nie. Hierdie verskynsel word van die vroegste tye af bestudeer en tog blyk dit dat die literatuur geen uitsluitsel bied oor watter benadering nou werklik die mees gewensde resultate lewer nie. Trouens die leser kom telkens onder die indruk van teenstrydighede en strydpunte tussen verskillende navorsers en skrywers wat elk 'n besondere benadering probeer regverdig.

Dit het derhalwe tyd geword om die motiveringsbegrip te ontleed in terme van basiese beginsels sodat die verskillende teorieë en benaderings ten opsigte van motivering in die regte bane geplaas kan word. In sodanige strukturering sal gepoog word om 'n wetenskaplike ontwikkelingsperspektief oor die motiveringsliteratuur weer te gee.

\section{DIE MOTIVERINGSBEGRIP}

Die begrip motivering is oorspronklik afgelei uit die Latynse begrip "movere" (om te beweeg) (Steers \& Porter, 1979). Beter gestel sou gesê kon word dat dit 'n proses is waardeur die mens in beweging gebring word. Hierdie proses is geleë binne die individu wat self beslis oor die rigting en vorm wat gedrag sal aanneem. Bevestiging van hierdie uitgangspunt word

\footnotetext{
${ }^{*}$ Versoeke vir afdrukke moet aan die skrywer gerig word.
} 
afgelei van die hedonistiese beginsel van motivering wat vandag nog algemeen in kontemporêre teorieë oor motivering aanvaar word. Die hedonistiese beginsel verklaar die struktuur van menslike gedrag in eenvoudige terme: die mens soek plesier en vermy pyn. Vanuit 'n motiveringsbenadering is alle menslike gedrag dus daarop gemik om die aangename na te speur en die onaangename te vermy. Van onmiddellike betekenis is die feit dat daar van positiewe sowel as negatiewe motivering gepraat kan word, en dat beide die twee rigtings wat motivering kan inslaan, ewe sterk kan wees. Dit sou dus verkeerd wees om van ongemotiveerde werknemers te praat, want die mens is altyd gemotiveerd in 'n bepaalde rigting.

Uit bogenoemde verklaring van menslike gedrag is dit belangrik om te besef dat motivering nie 'n geïsoleerde probleem in organisasies is nie, maar begryp moet word binne die konteks van 'n volledige sisteem van kennis wat nodig is om organisatoriese doeltreffendheid te bewerkstellig. Dit sal gevolglik nie veel help om volledig insig te hê in menslike motiveringsbeginsels as die leiers in organisasies nie in staat is om die motiveringsprosesse van werknemers in 'n positiewe rigting te kanaliseer nie. Ook beteken dit nie veel om motiveringsprosesse te begryp as die organisasieklimaat nie ingestem is om die bevrediging van menslike behoeftes te bewerkstellig nie. Negatiewe motivering is dus die gevolg van ander probleme in organisasies en selde die oorsaak van probleme wat ontstaan.

Vanuit ' $\mathrm{n}$ teoretiese beskouing is talle definisies van motivering reeds in die literatuur geformuleer. Vir die doeleindes van hierdie artikel sou 'n bespreking daarvan slegs verdere verwarring skep ten opsigte van basiese beginsels. Daar word dus volstaan met 'n praktiese werkbare definisie in terme van die argumente sover vermeld, naamlik: Motivering is doelgerigte gedrag. Die leser moet egter weer daaraan herinner word dat doelgerigte gedrag in 'n positiewe of 'n negatiewe rigting kan beweeg.

Om motivering tot basiese beginsels te vereenvoudig moet dit gesien word as 'n proses wat pas by hierdie definisie en as volg voorgestel kan word:

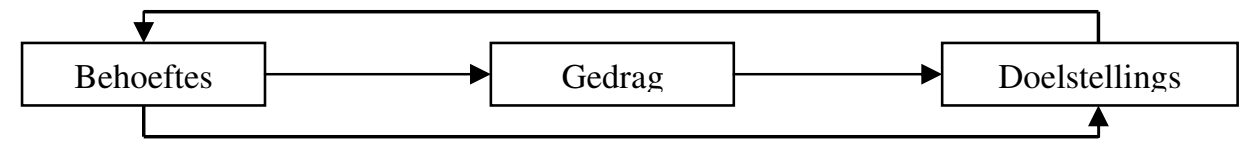

Hierdie proses is 'n vaste dogma in die Bedryfsielkunde, wat jare reeds bekend is en algemeen aanvaar word. 'n Verskeidenheid van teorieë is reeds rondom elkeen van hierdie begrippe in die motiveringsliteratuur gebou. Sommige teorieë begin by behoeftes wat in die proses van motivering gerig is op doelstellings. Ander begin by doelstellings wat gerig is op 
die bevrediging van behoeftes terwyl 'n derde groep konsentreer op gedrag wat gerig is tot bepaalde doelstellings ten einde sekere behoeftes te bevredig.

\section{TEORIEË VAN MOTIVERING}

Die verskillende motiveringsteorieë wat in die literatuur voorkom, kan kategoriseer word om in te skakel by bogenoemde proses.

\section{Behoefteteorië}

Hierdie teorieë staan ook bekend as inhoudsteorieë en draai basies rondom die eerste verklaring van menslike motivering, naamlik dat behoeftes die motiveringsproses aan die gang sit ten einde bepaalde doelstellings te bereik. Maslow (1943) se hiërargiese ontwikkelingsteorie bly steeds die basiese fondament van hierdie teorieë en is in industriële verband treffend deur McGregor (1960) se uitspraak verewig, naamlik - 'n bevredigde behoefte is nie 'n motiveerder van gedrag nie. Ten spyte van Herzberg (1966) se heftige ontkenning dat sy teorie geen verband toon met Maslow (1943) se werk nie, het 'n logiese beskouing dat geen ander gevolgtrekking as die oorspronklike behoeftes van Maslow slegs deur Herzberg in twee kategorieë geplaas is nie (Kyk figuur 1).

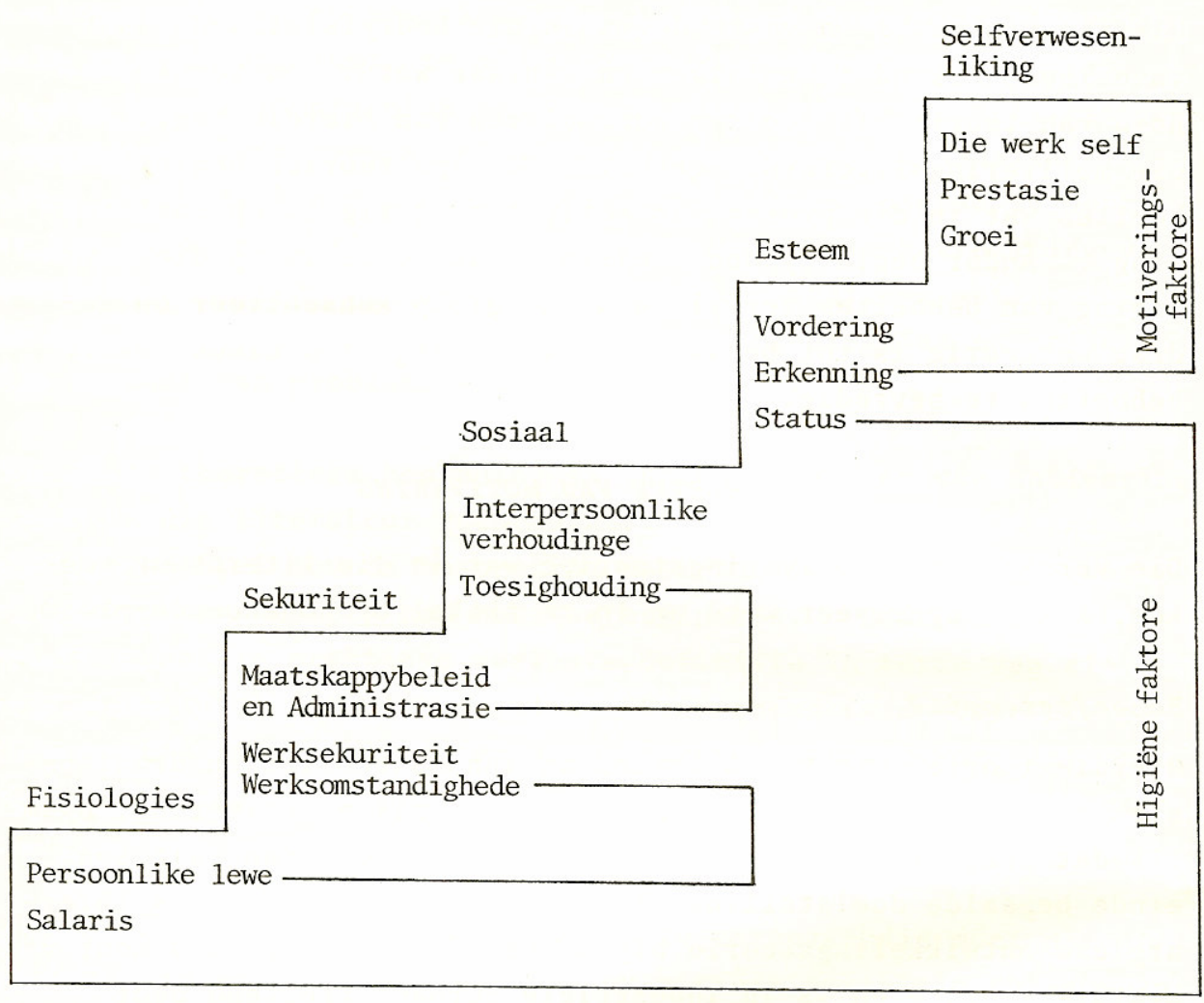

Figuur 1 : Die ooreenkoms tussen Maslow en Herzberg se teorieë. 
Vanuit ' $n$ teoretiese beskouing blyk die belangrikste bydrae van Herzberg dus dat hy die eerste persoon is wat die sogenaamde nulpunt in menslike motivering ontdek het (Kyk figuur 2).

\begin{tabular}{ccc}
\hline & Higiëne & Motiveerders \\
\cline { 2 - 3 } haat & 0 & + \\
\hline
\end{tabular}

Figuur 2: Die nulpunt in motivering

Hierdie verklaring dui daarop dat die teenoorgestelde van positiewe motivering nie noodwendig negatiewe motivering is nie, maar 'n gevoel van onverskilligheid wat by individue ontstaan. Daar moet veral erkenning gegee word aan die feit dat Herzberg nie die rol van die higiëne faktore negeer nie, maar as noodsaaklike middels beskou om te voorkom dat individue verby die nulpunt in 'n negatiewe motiveringsrigting beweeg.

Vanuit praktiese toepassingsoorwegings moet erkenning verleen word aan Herzberg (1966), Ford (1969) en Lawler (1973) vir die voortvloeisel van posverryking wat in die praktyk met goeie gevolge toegepas word. Posverryking moet ook gesien word as 'n tegniek wat die behoeftebegrip as uitgangspunt van motivering gebruik. Soortgelyk moet die affiliasiemotief van Schachter (1959) sowel as die groeiprosesmodel van Argyris (1964) onder hierdie groep geklassifiseer word.

Schachter het met sy affiliasiemotief veral die klem laat val op sosiale behoeftes wat menslike gedrag tot doelgerigte gedrag aktiveer. Argyris (1964) verwys na die veranderende behoeftepatrone wat die mens ondergaan vanaf die kinderstadium van afhanklikheid tot volwasse onafhanklikheid asook interafhanklikheid. Hierdie wisseling in behoeftepatrone word uitgelig as motiveringsfaktore wat bedryfsleiers in ag moet neem in die hantering van personeel.

Rondom die voorafgenoemde teorieë is geweldig baie navorsing gedoen. Uiteenlopende resultate is gekry en die vraag kan met reg gestel word waarom dit so is? Die belangrikste rede is waarskynlik dat die inhoudsteorieë poog om universele beginsels neer te lê en gevolglik nie genoegsaam voorsiening maak vir individuele verskille ten opsigte van menslike motiveringspatrone nie. 


\section{Doelstellings en Gedrag}

Die sogenaamde prosesteorieë of kognitiewe teorieë neem die begrippe doelstellings en gedrag as basiese beginpunte van motivering by die mens. Dit is egter wel moontlik om hierdie teorieë in twee groepe te verdeel ten einde die oorspronklike definisie van motivering op te klaar.

\section{Doelstellings}

In hierdie kategorie val veral die billikheidsteorie (Adams, 1963) (Weick, 1966) van motivering wat ook bekend staan as die sosiale vergelykingsteorie. Hierdie teorie gaan uit van die veronderstelling dat werksprestasie (of doelgerigte gedrag) bepaal word deur die graad van billikheid of onbillikheid wat deur die individu in die werksituasie waargeneem word. Die billikheidsgraad word definieer in terme van die verhouding tussen insette en uitsette as vergelykingsmaatstaf met die ratio van ander individue (Kyk figuur 3).

Individu

$\underline{\mathrm{A}}$

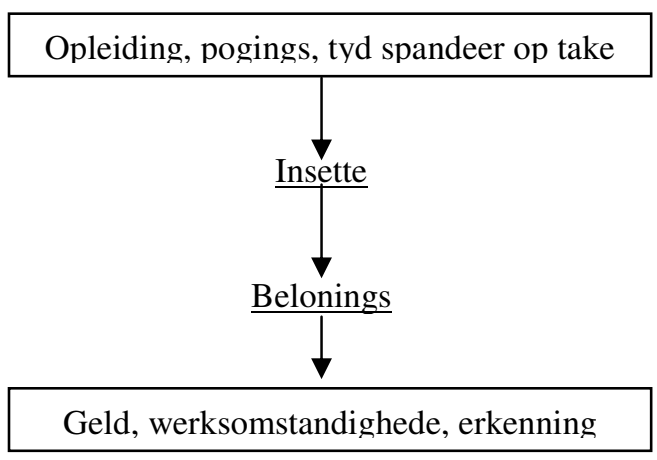

Individu

$\underline{\mathrm{B}}$

Figuur 3: Billikheidsteorie

Persoon A se werksprestasie word bepaal deur 'n voortdurende vergelyking met persoon B se inset/uitset verhouding, en andersom. Hoe meer billik die waargenome verhouding, hoe hoër prestasie en hoe meer onbillik die verhouding hoe laer sal prestasie wees. Onbillikheid kan dus as volg voorgestel word:

$$
\begin{array}{lll}
\mathrm{Au} & > & \mathrm{Bu} \\
- & < & - \\
\text { AI } & & \mathrm{BI} \\
\text { waar } & \mathrm{A} & =\text { Persoon A } \\
& \mathrm{B}=\text { Persoon } \mathrm{B} \\
\mathrm{U} & =\text { Uitsette (bv. belongings ens.) } \\
\mathrm{I} & =\text { Insette }
\end{array}
$$


Billikheid vind plaas indien

$\frac{\mathrm{Au}}{\mathrm{AI}}=\frac{\mathrm{Bu}}{\mathrm{BI}}$

Aangesien die relatiewe verhouding instrumenteel raak tot prestasie, is dit logies om te aanvaar dat pogings gerig sal word tot doelgerigte herstel van 'n wanbalans.

Doelwitbestuur word in die jongste literatuur ook meer en meer as motiveringstegniek aangebied (Organ, Hamner, 1982; Williams, 1978) en gevolglik is dit ook nodig om hierdie tegniek in die doelwitkategorie van motiveringsteorieë te plaas. In teorie berus hierdie tegniek op die beginsel van langtermyndoelwitte wat opgebreek word in korttermyneenhede. Hierdie eenhede kan gemotiveerde gedrag tot gevolg hê weens die moontlikheid van bevrediging van menslike behoeftes.

\section{Gedrag}

Moderne verwagtingsteorie met sy verskillende fasette soos deur verskeie navorsers aangetoon, verteenwoordig die gedagtegang dat gedrag die beginpunt van 'n kognitiewe motiveringsproses is. Volgens Vroom (1964) is motivering 'n funksie van ervaring, versterking en verwagtings wat die volgende formule aanneem:

\section{Motivering $=\Sigma($ Valensie $\mathrm{X}$ Verwagting $)$}

waar valensie beteken hoe graag die individu iets wil bereik (of vermy) en verwagting die antisipering van positiewe of negatiewe gevolge uitmaak. Die primêre uitgangspunt is dus dat die gevolge of doelwitte wat bereik sal word die bepalende faktore in doelgerigte gedrag word. Die relatiewe aantreklikheid van doelwitte skep dus die behoefte om gedrag te laat plaasvind. Hierdie benadering word meer duidelik illustreer deur die model van Porter en Lawler (1968) wat die volgende formule postuleer:

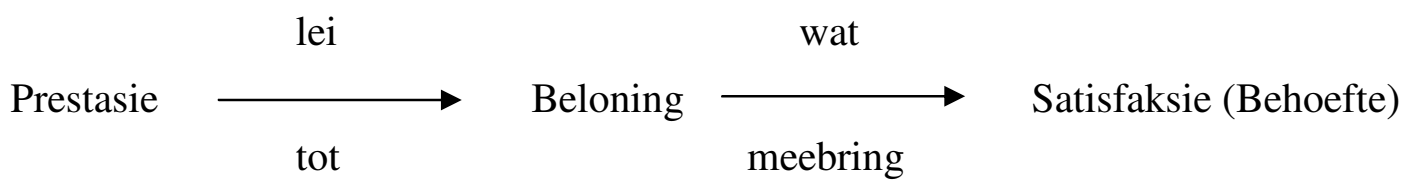


Dit is dus duidelik dat die basiese motiveringsproses soos in Figuur 1 uiteengesit is, hier net omgekeer word en van 'n ander kant af benader word.

\section{MOTIVERINGSDETERMINANTE}

'n Konseptuele beskouing van motivering na aanleiding van die verskillende teorieë wat reeds geformuleer is, vereis eerstens 'n sisteemoriëntasie tot die motiveringsveld. Reeds vroeër is vermeld dat motivering nie in isolasie gesien moet word nie maar as deel van totale menslike gedrag. Enige poging tot konseptualisering kan nooit 'n volledige beeld gee nie en moet dus as sodanig interpreteer word. Veranderlikes van menslike motivering in die werksomgewing kan hoofsaaklik in drie kategorieë verdeel word (Kyk tabel 1).

Elkeen van die begrippe in Tabel 1 is relatief sodra erkenning verleen word aan die invloed van individuele verskille op menslike gedrag. Omdat individuele eienskappe soos belangstellings, houdings en behoeftes van individu tot individu verskil, is dit net logies dat die impak van elkeen van hierdie faktore op motiveringsprosesse ook sal verskil. Soortgelyk sou verwag word dat die voorbeelde van werkseienskappe wat in Tabel 1 genoem is ook verskillende invloede op verskillende mense sal hê. Eweneens kan die invloed van die omgewing nie losgemaak word van individuele verskille nie.

$\underline{\text { TABEL } 1}$

\section{MOTIVERINGSDETERMINANTE IN WERKSOMGEWINGS} (aangepas uit Steers \& Porter, 1979, p.21)

\begin{tabular}{|c|c|c|}
\hline Individuele eienskappe & $\begin{array}{l}\text { Werkseienskappe } \\
\text { (voorbeelde) }\end{array}$ & Werksomgewingseienskappe \\
\hline 1. Belangstellings & $\begin{array}{l}\text { Tipes intrinsieke } \\
\text { belonings }\end{array}$ & $\begin{array}{l}\text { 1. Onmiddellike werksom- } \\
\text { gewing } \\
\text { - Gelykes }\end{array}$ \\
\hline $\begin{array}{l}\text { 2. Houdings } \\
\text { - tot self } \\
\text { - tot werk }\end{array}$ & $\begin{array}{l}\text { Die mate van } \\
\text { werksoutonomie }\end{array}$ & $\begin{array}{l}\text { - Minderes } \\
\text { - Toesighouers }\end{array}$ \\
\hline $\begin{array}{l}\text { - tot aspekte van } \\
\text { die werksituasie }\end{array}$ & $\begin{array}{l}\text { Die hoeveelheid } \\
\text { direkte prestasie } \\
\text { terugvoering }\end{array}$ & $\begin{array}{l}\text { 2. Organisatories } \\
\text { - vergoedingspraktyke } \\
\text { bonusse }\end{array}$ \\
\hline $\begin{array}{l}\text { 3. Behoeftes } \\
\text { (byvoorbeeld) } \\
\text { - sekuriteit } \\
\text { - sosiaal } \\
\text { - verwesenliking }\end{array}$ & $\begin{array}{l}\text { Verskeidenheid in } \\
\text { werksaktiwiteite }\end{array}$ & $\begin{array}{l}\text { individuele belonings } \\
\text { - organisasieklimaat }\end{array}$ \\
\hline
\end{tabular}


Wat die saak egter nog meer kompliseer, is dat 'n enkele eienskap ook 'n kumulatiewe effek op ander eienskappe kan hê. So byvoorbeeld sou die houding van 'n individu tot sy werk (individuele eienskap) bepaal in watter mate intrinsieke belonings (werkseienskap) sy prestasie binne 'n gegewe organisasieklimaat (werksomgewingseienskap), beïnvloed.

Die aanklag wat dikwels gehoor word dat sekere teorieë nie in die praktyk realiseerbaar is nie, word miskien duidelik illustreer deur bovermelde uiteensetting. Juis die feit dat verskillende teorieë op die verklaring van bepaalde motiveringsdeterminante afgestem is, vereis omsigtigheid by direkte praktiese toepassing.

Die inhoudsteorieë waarna vroeër verwys is, is in wese individuele motiveringsteorieë en konsentreer dus op die individuele eienskappe van Tabel 1. Dit is dan ook onbillik om te verwag dat byvoorbeeld Maslow se teorie 'n totale en omvattende verklaring van motivering moet gee. Die eng beskouing van die inhoudsteorieë is dan ook hulle grootste beperking.

Sommige van die prosesteorieë poog om meer as 'n enkele kategorie te betrek in die formulering van die teorie. Die billikheidsteorie sentreer byvoorbeeld rondom die verhouding tussen individuele eienskappe en werksomgewingseienskappe (Tabel 1). Die houding van die individu tot sy werk word byvoorbeeld beïnvloed deur sy waarneming van die billikheid van vergoedingspraktyke in die organisasie.

Die verwagtingsteorie van motivering as synde die mees kontemporêre teorie tot ons beskikking is die enigste wat 'n sinvolle poging aanwend om aldrie eienskappe binne die konteks van 'n enkele teorie te verklaar: Die valensiebegrip verklaar tot 'n groot mate die kwessie van individuele verskille. Die werkseienskappe word deur die begrip instrumentaliteit ontleed terwyl werksomgewingseienskappe soos vergoedingspraktyke deur die verwagtings/valensie konsepte verklaar word.

Vanuit hierdie gedagtegang is dit dus duidelik dat die verwagtingsteorie van motivering die beste poging tot dusver is om motiveringsdeterminante te verklaar.

Vanuit 'n ander hoek belig, sou 'n mens motiveringskragte by die individu in twee groepe kan verdeel nl. ekstrinsieke en intrinsieke motivering. Hier vind ons weer dat die inhoudstoerieë in hoofsaak op intrinsieke motivering konsentreer (vergelyk Maslow se behoeftehiërargie en Herzberg se motiveringsfaktore). Prosesteorieë poog weer om beide intrinsieke en ekstrinsieke motiveringskragte in te sluit. Weereens is die verwagtingsteorie en veral dan Lawler (1970) se voorstelling daarvan wat die aandag verdien (Kyk figuur 4). 


$\begin{aligned} \text { Motivering } & =\left[\begin{array}{c}\text { Intrinsieke } \\ \text { motivering }\end{array}\right. \\ \text { waar: } \quad \mathrm{E}] & \mathrm{C}\end{aligned}$

Figuur 4: Intrinsieke en Ekstrinsieke motivering binne die verwagtingsmodel.

Die $(\mathrm{E} \rightarrow \mathrm{P})$ verwagting of die waarskynlikheid dat die individu in staat sal wees om deur ' $\mathrm{n}$ groot hoeveelheid pogings wel 'n eerste vlak uitkoms te bereik, is niks anders as die houding van die individu teenoor homself en sy waardering van sy selfkapasiteit nie. Die (V) valensie is die intrinsieke voorkeur/afkeur wat die individu vir ' $n$ bepaalde tweedevlak uitkoms het. Die mate waartoe die $(\mathrm{P} \rightarrow \mathrm{O})$ verwagting, gedrag beïnvloed, word bepaal deur die sekerheid wat die ekstrinsieke omgewing bied dat verwagte belonings realiseer sal word.

Vanuit 'n teoretiese perspektief moet 'n mens dus tot die gevolgtrekking kom dat die verwagtingsteorie van motivering die mees gevorderde teorietegnologie is waaroor die akademikus en die praktiese implikasies van motivering vir bestuurslui, word weer na hierdie standpunt verwys.

\section{DIE MOTIVERING VAN DIE NUWE GENERASIE WERKNEMER}

In praktiese terme blyk dit moontlik om die voorafgaande teoretiese uiteensetting tot 'n enkele model te reduseer, wat dan as basis kan dien vir die bestuurder wat erns het met die probleem van motivering. Hierdie model word in Tabel 2 uiteengesit.

Die teoretiese analise in Tabel 2 is ' $n$ kort samevatting van die besprekingspunte wat tot dusver geopper is. Die praktiese implikasie gedeelte (dele X, Y en Z) in Tabel 2 het verdere verduideliking nodig:

$\mathrm{X}$ : Wat dikwels in die praktyk waargeneem word as 'n gebrek aan motivering is niks anders as 'n gebrek aan kennis aan die kant van die individuele werknemer nie. Na aanleiding 
van die individuele eienskappe (vergelyk Tabel 1) en die intrinsieke aard daarvan behoort aandag gegee te word aan opleiding van werknemers om hulle bewus te maak van die latente potensiaal waaroor hulle beskik. Terselfdertyd kan gedragsmodeleringstegnieke aangewend word om positiewe individuele eienskappe te illustreer. Bestuur behoort ook pogings aan te wend om die individuele werknemer sensitief te maak vir die ontdekking en ontwikkeling van eie potensiaal deur byvoorbeeld die takseersentrumtegniek.

TABEL 1

KONSEPTUELE MODEL VAN PRAKTYKGERIGTE MOTIVERING

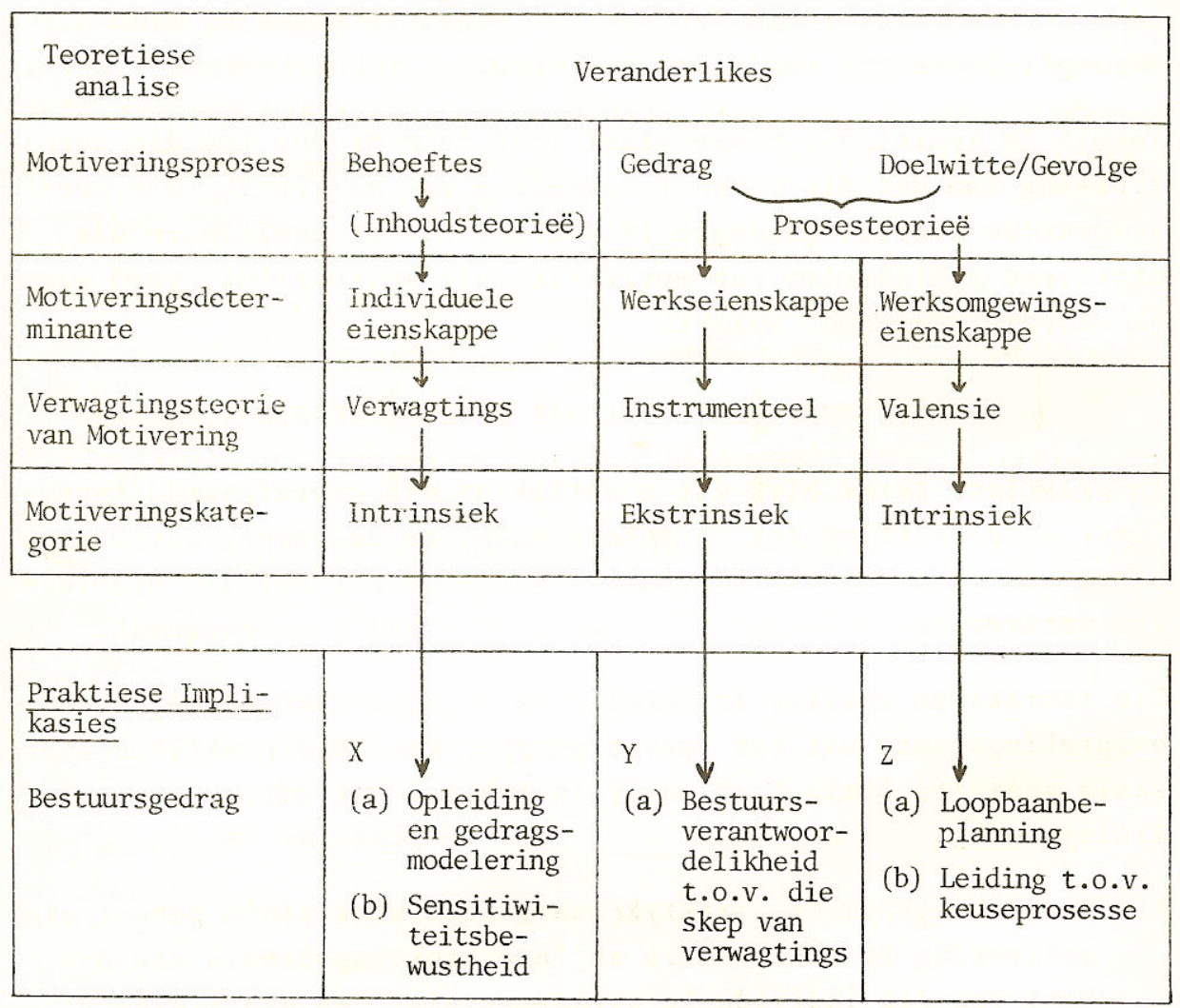

Y : Die sekerheid van die werknemer dat indien hy/sy goeie prestasie lewer dit ongetwyfeld opgevolg sal word deur bepaalde belonings en kan nie geringskat word nie. Bestuur het dus 'n bykans etiese verantwoordelikheid ten opsigte van verwagtings by ondergeskiktes in opvolging van verlaagde prestasies.

$\mathrm{Z}$ : Deur loopbaanbeplanning waar die individu se besondere kort en langtermynvoorkeure in ag geneem word, kan bestuur 'n bydrae lewer tot die langtermyn satisfaksie van individuele werknemers. Ook kan die bestuurder hulp verleen aan ondergeskiktes deur leiding (en selfs opleiding) ten opsigte van individuele keuseprosesse. 
Die kritiese begrip wat uit hierdie bespreking na vore kom is werkverwante gedrag. Dit wat die bestuurder doen sowel as dit wat die werknemer geleer word om te doen. In hierdie verband word die standpunt van Odiorne (1980, p.106) ten sterkste ondersteun: "The point made here is that we simply stop talking about the subject of motivation theory and turn our attention to something we can accomplish with our own skills - the changing of job behavior".

\section{Bestuursimplikasies}

Die toepassing van hierdie konseptuele model van praktykgerigte motivering, het verskeie implikasies (Leidecker en Hall, 1980; Steers en Porter, 1979 en Miner, 1980) vir bestuur, naamlik:

- $\quad$ Bestuurders behoort ' $n$ aktiewe rol te vervul in die bestuur van motiveringsprosesse. Motiveringsbestuur is bewuste en doelgerigte gedrag wat nie sommer net plaasvind nie.

- $\quad$ Bestuur behoort op 'n sistematiese wyse inligting in te win ten opsigte van wat werknemers werklik in hulle werk soek (die persoonlike waarde van belonings of valensies).

- $\quad$ Bestuur behoort seker te maak dat werknemers hulle werkvereistes begryp sodat pogings nie verlore gaan nie.

- $\quad$ Enige poging tot verhoging in die motiveringspeil van werknemers moet voorafgegaan word deur 'n selfondersoek aan die kant van bestuur. Is bestuur bewus van hulle eie sterktes en tekortkominge? Is hulle seker van hulle eie behoeftes en verwagtings van hulle werk? Eers nadat hierdie vrae beantwoord is, kan bestuurders poog om ander te help.

- Die belangrikheid van die herkenning van individuele verskille moet weer beklemtoon word. Bestuurders moet sensitief wees vir variasies in werknemersbehoeftes, vermoëns en karaktertrekke. Ook moet bestuur bewus wees daarvan dat werknemers verskil ten opsigte van voorkeure wat geheg word aan bepaalde inkomste uit prestasie.

- $\quad$ Bestuur moet die aard van take wat deur ondergeskiktes verrig word ontleed en voortdurend op die uitkyk wees vir take wat groter uitdagings, diversiteit en geleenthede vir persoonlike groei, bied.

- $\quad$ Om hoër motiveringspeile te kan bereik sal bestuur genoodsaak wees om werknemers betrokke te laat raak by werksprosesse wat hulle persoonlik raak. 
- $\quad$ As voorvereiste vir ' $n$ gemotiveerde arbeidsmag, sal bestuur vaardig moet raak in objektiewe prestasiebeoordeling en terugvoeringsprosesse aan individuele werknemers.

- Bestuur sal verplig wees om werkshoudings op kontinuerende basis te meet en te monitor.

\section{OPSOMMING}

Die indruk wat verskillende motiveringsteorieë in die literatuur skep, is dat elke teorie ' $n$ unieke verklaring gee van gemotiveerde gedrag. Indien die basisbegrippe en die motiveringsproses egter as ankers gebruik word om teorie ë te ontleed is dit moontlik om aan te toon dat teoriebou in die motiveringsliteratuur, niks anders is as beligtingsaspekte van dieselfde fenomeen nie. Die beligtingskant van kontemporêre teorieë is weliswaar meer werksverwant en die implikasies en toepassing daarvan word aangetoon.

\section{VERWYSINGS}

Adams, J.S. Wage inequities, productivity and work quality. Industrial Relations, 1963, 3, 9. Argyris, C. Integrating the Individual and the Organization. New York: John Wiley, 1964. Ford, R.N. Motivation through the Work Itself. New York : American Management Association, 1969.

Herzberg, F. \& Lawler, E.E. Job attitudes and employee motivation: Theory research and practice. Personnel Psychology, 1970, 23, 223-237.

Lawler, E.E. Motivation in Work Organizations. Monterey: Brooks, 1973.

Leidecker, J.K. \& Hall, J.J. Motivation: Good theory - poor application. Training and Development Journal, 1981, June, 152-155.

Maslow, A.H. A theory of human motivation. Psychological Review, 1943, 50, 370-396.

McGregor, D. The Human Side of Enterprise. New York: McGraw-Hill, 1960.

Miner, J.B. Theories of Organizational Behavior. Hinsdale: Dryden, 1980.

Odiorne, G.S. An uneasy look at motivation theory. Training and Development Journal, 1980, June, 106.

Organ, D.W. \& Hamner, W.C. Organizational Behavior: an Applied Psychological Approach. Plano: Business Publications, 1982.

Porter, L.W. \& Lawler, E.E. Managerial Attitudes and Performance. Homewood: Richard D. Irwin, 1968.

Schachter, S. The Psychology of Affiliation. Stanford: University Press, 1959.

Steers, R.M. \& Porter, L.W. Motivation and Work Behavior. New York: McGraw-Hill, 1979. Van Wyk, A.J. Enkele perspektiewe op bestuursopleiding en -ontwikkeling. Perspektiewe in die Bedryfsielkunde, 1978, 4(4), 23-39.

Vroom, V.H. Work and Motivation. New York: Wiley, 1964.

Weick, K.E. The concept of equity in the perception of pay. Administrative Quarterly, 1966, $11,414-439$. 
Williams, J.C. Human Behavior in Organizations. Dallas: South Western Publishing Co., 1978. 